\title{
Becoming a Leader in the Hospitality Industry
}

Timothy Hinkin

Leadership has been defined in many ways, but the essence of leadership involves influencing people toward a desired objective. Leaders do not push followers-they pull them. While management is often concerned about stability, efficiency, and control, leadership is focusing on innovation, adaptation, and employee development. Management focuses on coping with the day to day, while a true leader is looking into the future. A manager can develop a brilliant marketing campaign, create an innovative strategy for growth, and design the most efficient work processes, but if the followers don't engage effectively in the implementation of these initiatives, these efforts will fail. Leadership does not exist in a vacuum but emerges only with the consensus of followers. So, simply being in a leadership position does not automatically make you a leader. Instead, others decide whether you are a leader. In this chapter, I discuss how you can achieve this status.

In truth, we are still learning how leaders develop (see Table 6.1). I like to think of leadership as an evolutionary process, from "little 1" to "BIG L." Every individual in any managerial position has a sphere of influence, and within that sphere they can have either a positive or negative impact. The impact may be "little 1" if you are the front-desk manager of a small hotel, or "Big L" if you are the CEO of an international restaurant company. Regardless of the size of the sphere of influence, both situations give you the opportunity to be an effective leader. Your success in the position of "little 1" may result in the increase of your sphere of influence with the eventual progression to the role of "BIG L."

Table 6.1

- Evolution of Leadership Research

\begin{tabular}{lll}
\hline Decade & Culture & Leadership \\
\hline Pre-1950 & Hierarchy & Control \\
$1950 \mathrm{~s}$ & Organization & Supervision \\
$1960 \mathrm{~s}$ & Systems & Administration \\
$1970 \mathrm{~s}$ & Strategy & Management \\
$1980 \mathrm{~s}$ & Innovation & Entrepreneurship \\
$1990 \mathrm{~s}$ & Diversity & Team Building \\
Post-2000 & Community & Relationships \\
\hline
\end{tabular}


You may find the answers to the following questions to be revealing with respect to your current leadership effectiveness:

- Are your subordinates willing to give a little extra when needed?

- Have any of their ideas been implemented recently?

- How many of your subordinates have been promoted to other parts of the organization?

- Has there been resistance to your recent efforts to institute change in work processes?

- Do you feel comfortable delegating important tasks to subordinates?

- What happens when you are not there?

You can figure out the correct answers to these questions, but the point of this exercise is to get you thinking about your leadership skills and spark enough interest to read and explore this chapter for yourself.

As I said, we're still learning about leadership and how leaders operate, but we've begun to nail down some basic principles, as I'll discuss in a moment. Table 6.1 shows leaders as being in an era of relationship building. Even if this is just another phase that we're passing through, the fact is that as a leader today, you need to develop relationships, defined as an emotional or other connection with your employees. People follow leaders because the leaders connect with them in some significant way. This model certainly fits the hospitality industry, with its labor-intensive operations and focus on people. Let's look at how one goes about developing these relationships to become an effective leader. The five steps that I offer in this chapter are based on an extensive body of research that examines the phenomenon of leadership in a variety of contexts, including the hospitality industry. They are: (1) be self-aware, (2) understand your organization, (3) establish objectives and provide guidance toward those goals, (4) acknowledge good performance and correct poor performance, and (5) be flexible and willing to adapt.

\section{Step 1: Understand Yourself}

The importance of self-knowledge may seem obvious, but it is amazing how many managers really don't have a good understanding of their own behavioral patterns and internal motivators. Nor do they see how they come off to other people. They tend to have a single preferred management style, which cannot be appropriate in every situation, and they often don't realize the impact of their actions on others. 
To use myself as an example of the importance of self-knowledge, prior to returning to graduate school to pursue my MBA I worked for two major hospitality organizations. I wasn't happy in either one, but I could never figure out why. During my MBA program, I undertook several personality assessments that helped me enormously in understanding myself. I learned that I have an extremely high need for autonomy. That would explain my frustration with the corporate structure with its strict policies, centralized decision making, rigid hierarchies, and top-down management. In another personality assessment, the widely used Myers-Briggs test, I learned that I am what Myers-Briggs calls an ENTP personality type. As an "E" I get my energy from being around people, and this type is described as being theoretical, creative, analytical, and questioning-a good profile for an academic, but perhaps not so great for the structure in the corporate world. ${ }^{1}$ I entered my MBA program fully intending on returning to some part of the hospitality, industry, but with the insight and introspection I gained in the program, I decided to totally change the direction of my career and consequently my life. Both of the companies I worked for are successful and well regarded-nothing is wrong with them. With self-knowledge, I now know that working there was just wrong for me. This was important information, and it has had a tremendous impact on shaping my career as a professor.

Assessments of this type are not mere parlor games, but can provide powerful insights into your motivations and behavior. In recent years there has been increased research into what has been termed emotional intelligence, or EQ, defined by Daniel Goleman as the ability to manage ourselves and our relationships effectively. EQ is characterized by four traits, the first .being self-awareness, as we have been discussing here. ${ }^{2}$ The second dimension is self-management, demonstrated by self-control and being able to adapt appropriately to a situation. This involves the ability to adjust easily to changing situations without becoming emotionally upset. The third dimension is social awareness, which is empathy for others and an understanding of organizational dynamics. With high social awareness, you are sensitive to the emotions of others and you understand others' perspective on issues. The fourth trait is social skill, which includes effective communication, conflict management, and persuasiveness. With this skill you are able to constructively manage disagreements and influence others. In sum, EQ is an assessment of how well we understand ourselves and how we relate to others.

You might benefit from a brief period of introspection spent asking yourself how you rate on these dimensions. Better yet, getting feedback from trusted colleagues could be even more helpful. Because of the high degree of interpersonal interaction with both employees and guests in the hospitality industry, EQ is especially important to hospitality leaders. 
A substantial body of research has shown that executives who possess a higher degree of EQ received more favorable performance reviews and their organizations achieved greater financial success. As an example, in September 2007, Starwood Hotels and Resorts hired Frits van Paasschen as its new CEO. He had held executive positions at Disney, Nike, and Coors, but admitted knowing little about the hotel industry. He was hired for his leadership ability, and the following quote reflects his management style: "What I learned is to work hard, treat everyone well, and listen," he says. "It's more about effort than ability. We all know brilliant people who haven't had a very successful life. ${ }^{3}$ His leadership philosophy and career success suggest that he has a high EQ. In July 2010 Starwood's stock price was up over 100 percent from the previous July in a year when many hotel companies were suffering.

Peter Drucker, the noted management scholar, suggests that it is critical to understand your strengths and weaknesses, how you interact with others, and what your values are. ${ }^{4}$ In this context, you need to give thought to what is really important to you. Your values are reflected in your behavior. We have learned that subordinates are constantly observing managers to see if their actions match their words. Thus, they soon learn to distrust managers who exhort people to be creative and think out of the box but then are all over them when someone fails, or a manager who prides himself on being open to suggestion but reacts with hostility when his ideas are questioned. As explained further in Chapter 31, studies by my colleague Tony Simons and others have shown that behavioral integrity, the consistency between words and deeds, is related to a number of organizational outcomes including reduced employee turnover and increased profitability. You are a role model, whether you are setting a good example or a bad one. ${ }^{5}$

We all have a preferred way of leading that is influenced by our personality, education, and experience. Clearly, though, your preferred way of leading is not going to fit every situation, and so we need to be aware of when we should behave in a particular way or move away from our preferred leadership style. ${ }^{6}$ Goleman discusses the following six leadership styles:

1. Coercive: Demands immediate compliance

2. Authoritative: Mobilizes people toward a vision

3. Affiliative: Creates harmony and builds emotional bonds

4. Democratic: Forges consensus through participation

5. Pacesetting: Sets high standards for performance

6. Coaching: Develops people for the future 
Do you see a style on that list that sounds like yourself? Or perhaps a blend of styles? Understanding your preferred leadership style is important because it's a starting point for how you would prefer to lead. The key to leadership is to determine when one style will be effective and when it's time to switch to another. Affiliative leadership might be ineffective in some situations when coercive leadership would be needed. If you are first aware of your behavioral preferences, then you can work on adjusting your style to the situation. A combination of authoritative, democratic, and coaching, for example, is a powerful leadership repertoire. Interestingly, research has shown that coaching is the least used leadership style, yet it can be one of the most beneficial for the long-term success of an organization. Self-awareness and recognizing how you affect others is the first step in becoming a successful leader.

\section{Step 2: Understand Your Organization}

When asked to describe their particular organization, most managers discuss hierarchical reporting relationships and rely on the most recent organizational chart, which might look something like Figure 6.1. These typical organization charts seldom mention customers, either internal or external, or how work actually flows through the organization. To learn about your organization, you need to understand your organization as a system. ${ }^{7}$ An organization is much like the human body, with organs serving as functional areas, the skeleton as the structure, and the circulatory and nervous systems providing coordination and communication. If any part of this system is not functioning properly, the whole organism falters. There is a strong sense of interdependence that exists in the human body, and also in and among organizations.

Hospitality organizations exist in a dynamic environment that contains competitors, customers, suppliers, and government-all of which can affect the company. Communicating with these entities is also important, as they provide resources and information necessary for the success of the organization, whether it's Smith Travel Research for its useful hotel benchmarks or the National Restaurant Association, with its educational and lobbying efforts. Sysco Corporation's business model, for instance, is based on forming relationships with its 400,000 customers. In 2009 , Sysco was rated number one by Fortune's "World's Most Admired Companies" in the Wholesale Food and Grocery Division.

Every organization has several interdependent key processes that have substantial impact on customers. At the School of Hotel Administration, the three most critical processes are admissions, education, and placement. We also have a number of important ancillary and support functions, such as alumni affairs, development, information technology, and human resources. We must be certain that 
the key processes are in alignment. The process starts with admissions, which includes activities such as determining where to put our recruiting efforts, and whom to admit, based on our established admissions criteria. Those criteria are driven by our success at placement and by feedback from industry. The education process is informed by our research and supported with classroom technology, and responses from industry also influence the content in the curriculum. Placement has three major processes: industry outreach, on-campus recruiting, and career tracking. The relationships among the key processes are illustrated in Figure 6.2.

Figure 6.1

Formal Organization Chart

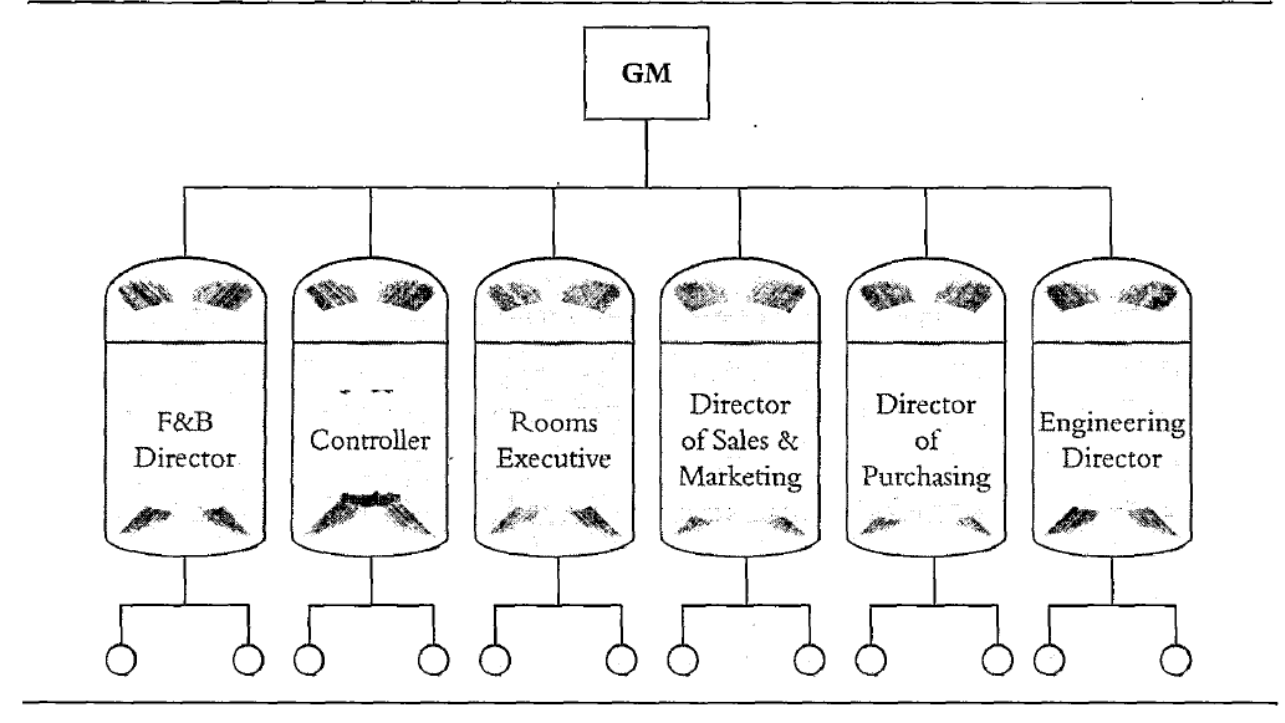

Although I have simplified the model, it illustrates the interdependent relationships that exist among the processes. If we accept the right students and provide the appropriate education, recruiters will hire them. This benefits the hospitality industry and fulfills our mission, which drives the alignment that is designed to "Prepare Leaders for the Hospitality Industry." That means we want to attract a student with a particular profile, provide the education that contains the appropriate content at a level of sufficient rigor, and place graduates in management positions that utilize their intellect and education. Feedback from the industry and recruiters is essential in ensuring that we are attracting the right students and preparing them well. Needless to say, the support functions contribute to our success. If any part of this system fails, the whole system fails. The same is true for any hospitality organization. 
Figure 6.2

Systems View-Key Processes

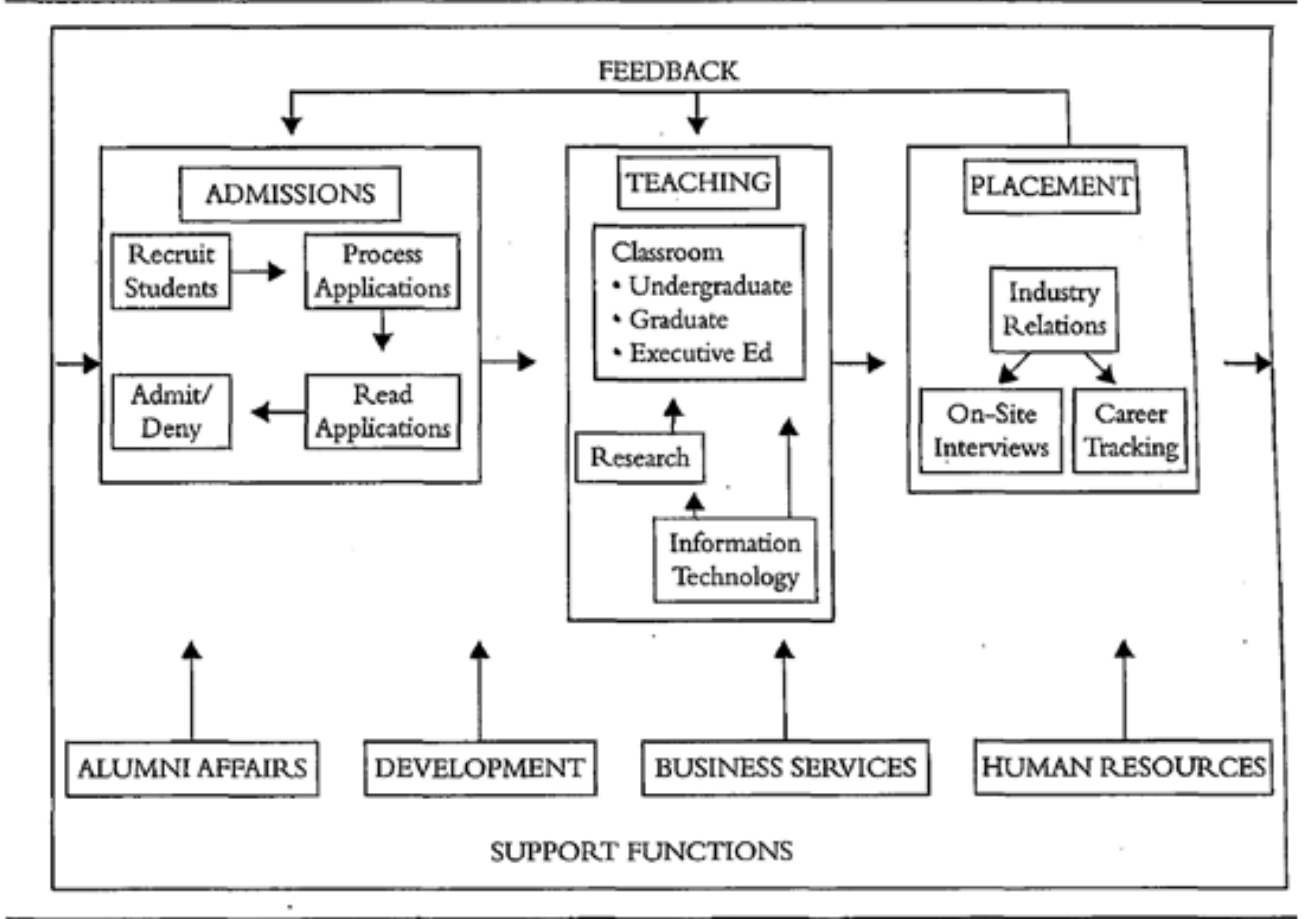

Darden Restaurants provides an excellent example of a company where top leadership understands the organization and its operations. They have identified the key interfaces that exist between internal and external customers, managers, and purveyors, and have developed a sophisticated distribution system that allows the firm to meet the needs of all of its constituencies. When they open a new restaurant, the delivery trucks are packed and deliveries timed so the items that are needed first arrive first. As a result, the restaurant can be up and operating within a few days after the first delivery. This does not happen by chance but because the leadership understands the interdependencies involved in opening a restaurant.

To truly understand organizations, however, one must go beyond the formal organization chart. Managers tend to manage vertically and functionally, looking down rather than across their organizations. The danger of this approach is that a manager may not recognize the interdependencies that exist. There are important critical interfaces in every organization such as between housekeeping and the front office or banquets and stewards, where managers often end up taking adversarial positions. Leaders, however, understand their organizations as comprising a number of interdependent processes, and they manage the "white space" on the organizational chart that exists between functional areas. 
Informal organizations are "webs of relationships" that transcend the formal organization chart. An analogy would be social media networks, because the informal network may communicate the way friends do on Facebook. That network comprises communication lines and hubs that create a network of relationships that does not show up anywhere on the organization chart, but is enormously powerful. ${ }^{8}$ Managers who either ignore or can't see these informal networks are at a distinct disadvantage because research has shown that better understanding of these networks has positive impacts on organizational performance. Leadership is all around you if you pay attention, and informal leaders can be a tremendous asset if their goals are in alignment with those of the organization.

Figure 6.3 presents an example of an informal communication network. You will note that Bill and Fran seem to occupy communication hubs, and that Fran's network is composed exclusively of women, with the exception of her contact with Bill. Don is isolated, while Art and Will seem to rely on Gus, and Tom communicates only with Bill. From this analysis, we can conclude that Bill is influential in the informal organization. Importantly, his position on the formal organization chart might not reveal this influence. Don, however, is so far removed from the action that he is not likely to have a good understanding of what is going on in the organization. That situation might be troublesome if he occupies a prominent position in the formal hierarchy. As a leader, you need to learn about your informal organization and then you can manage it effectively. A perceptive leader may hesitate to promote, say, Art over Bill, even if Art has superior technical expertise because, despite Art's skill and knowledge, he has not developed the relationships with others that would help him be successful. This is a typical example of how your organization goes far beyond what is shown on the organizational chart. Again, the clearer your understanding of the interdependencies and informal relationships that exist, the more effective you can be. 
Figure 6.3

Informal Communication Network

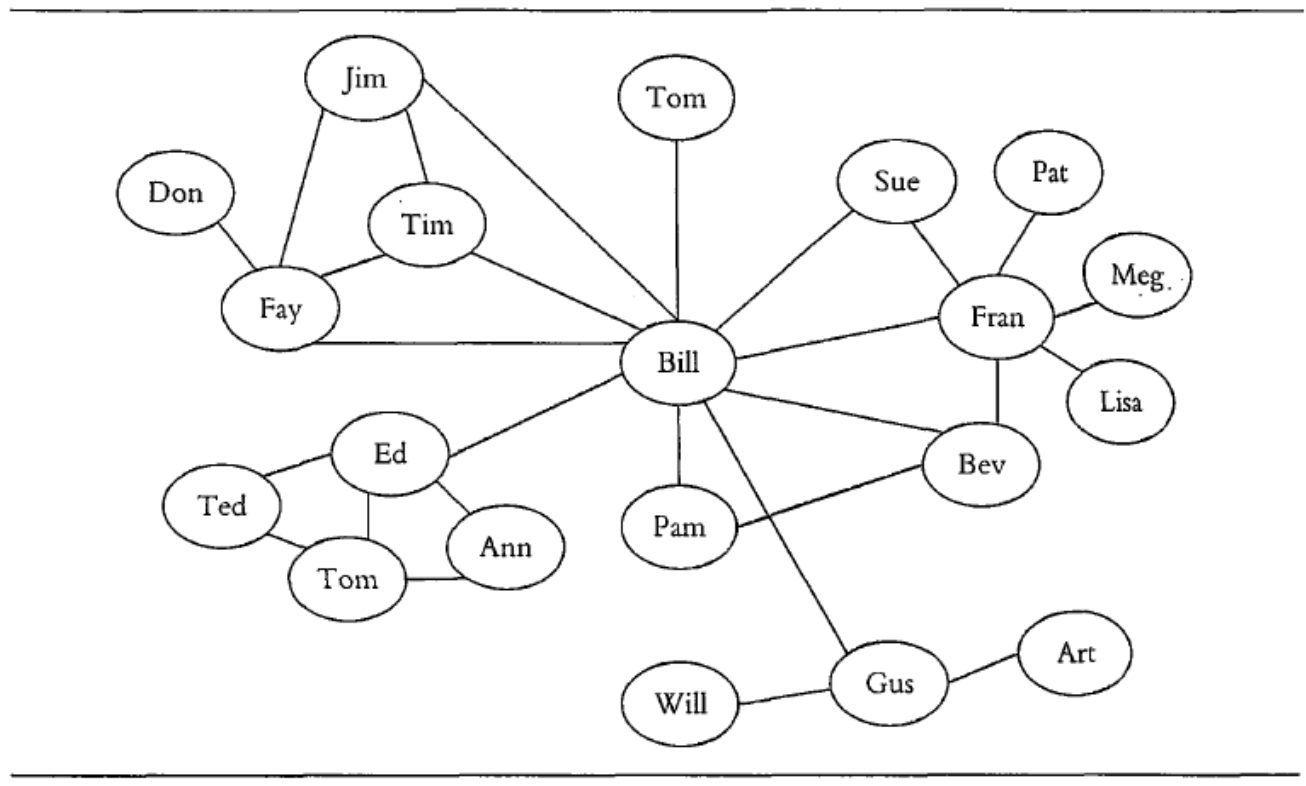

Step 3: Establish Objectives and Provide the Direction

This step starts by determining the objective of your organization. You need to know what you are really trying to achieve. Are you in business to satisfy the guest, for instance, or to maximize profitability-or can you do both? If you are in business to please the guest, your daily decisions will probably be different than if you are attempting to maximize profitability. People at all levels need to understand the overriding objectives of the organization, and these goals need to be aligned with department goals and functional practices as they cascade down through the organization. People can relate to an objective that they understand and accept.

The organization's overall goals should be driving the goals for each manager. Every manager has a sphere of influence, and you should be able to state what are you trying to achieve in your sphere of influence. Beyond that, your subordinates and colleagues also should be able to correctly describe your goals. Leadership at all levels begins with being able to articulate a goal or vision that followers can understand and internalize. That goal for "little 1" leaders might be to reduce to five minutes the time it takes to clear and reset a table or to increase market share by 10 percent. For "BIG L" leaders, an objective might be to have 20 hotels open in Asia by 2015. The sum total of these spheres of influence is to design the organization and work processes so that they are aligned with the overall organizational objectives, together with performance management systems that are designed to reinforce the vision. 
People need to .know what they are doing, why they are doing it, and how it fits into the big picture. For this reason, you need to continually remind people of the organizations goals. Research that examines various ways of influencing others has found that the most effective means of influencing others is by rational explanation. Extending this principle to the hospitality industry, your employees should have been given (and should be able to state) a rational explanation of why they are doing what they do. Much of the front-of-the-house work involves direct interaction with a customer or guest, and I think we can agree that the objectives and outcomes in this area are fairly obvious. The purpose of activities in the back of the house may not always be so clear cut, as some input-output relationships are either not recognized or not acknowledged.

When I visit hospitality organizations, I often ask employees why they are doing whatever task they are involved in. The answer is usually either "I was told to do it this way" or "that is the way we have always done it." As a leader, you need to counteract that type of impression so that all employees understand how their task contributes to the overall guest experience, or who their internal customer is. Not only do you need to explain why the work is important, but you need to make sure employees understand that they are appreciated for doing it. Having clean glassware is more important to most guests than meeting the chef, for instance, yet the steward department may be the hotel's least appreciated and most ignored department. Thus, it's essential that you let people know how their efforts relate to the achievement of the organization's overall objectives.

Bill Marriott's approach provides an excellent example of clearly articulating a vision that reflects the values of an organization. He states that "if we take care of our employees they will take care of our guests." ${ }^{9}$ This simple idea so clearly articulated has for decades provided guidance to everyone in the organization about what is important and how individuals treat each other. I don't need to also mention that this has been a successful approach, but I will point out that Marriott has well over 3,000 hotels worldwide with revenues in excess of $\$ 12$ billion. Not coincidentally, in recent years, it has also been one of only two hotel companies that have been consistently on Fortune's "100 Best Companies to Work For." The other is Four Seasons Hotels and Resorts, founded by another effective leader, Isadore Sharp. He also clearly stated his vision for a hotel that featured superior design, topquality amenities, and, above all, a deep commitment to service. He recently wrote a book entitled Four Seasons: The Story of a Business Philosophy that describes the importance of visionary leadership.

You don't need to write a book to state your organization's purpose, but you do need to be able to state it clearly and make sure that everyone in the organization also has the same goals. 


\section{Step 4: Acknowledge Good Performance and Correct Poor Performance}

With a clear objective in place, your reward systems must reinforce your organizations objectives and culture. We have all seen companies that fail to reflect their mission statements or codes of conduct in their performance management program. The most successful firms align rewards with objectives. American Express, for instance, has a set of "Blue Box Values." A key such value is: "We value our people, encourage their development, and reward their performance." To reinforce this value, senior leadership is evaluated using a 360-degree performance management process on eight leadership competencies. Four of those competencies focus on quantitative business results, while the other four focus on effectively leading people. The four leadership competencies are: demonstrates personal excellence, communicates effectively, builds and leverages relationships, and creates an environment where cross - team working is effective both internally and externally. Each of these competencies is assessed by specific behaviors such as "actively listens and incorporates input from others" and "shares critical expertise and knowledge to support partners and colleagues."

Similarly, Darden Restaurants separates their performance management systems into two primary categories, "what" a manager does, and "how" he or she does it. The "what" category is composed of four objectives: financial results, impact on the guest, employee development, and process excellence. The weighting for each of these objectives is tailored to the individual based on their responsibilities. The "how" category comprises four leadership competencies: personal leadership, people leadership, business leadership, and results leadership. The fact that so much emphasis in both organizations is placed on leading and developing subordinates sends a message about what is important and reinforces each company's culture and values. As a result, leaders develop leaders, not followers.

Beyond the formal reward systems the day-to-day interaction between a manager and subordinates provides many opportunities to respond to performance. When people perform well, a leader can either respond to that performance, which is termed contingent reward, or not, which is termed reward omission. The same is true for poor performance, although the choices there are contingent punishment or punishment omission. There is no money involved in these responses; it is simply a matter of responding to subordinates' performance in an appropriate manner.

In the popular series of books based on the One Minute Manager, Kenneth Blanchard exhorts you to actively look for opportunities to recognize good performance. ${ }^{10}$ Similarly, my own research examining reinforcement behaviors found that what people want is acknowledgment of good 
performance. We found that use of contingent rewards had strong positive impacts on subordinates' behavior and their attitudes about their manager. We also learned that satisfaction and performance of high performers who do not receive acknowledgment will decline over time, and eventually they may leave. By the same token, counter to intuition, my research also found that people want to know when they are performing poorly, and it is leadership's responsibility to correct the performance deficiency. Again, this is part of acknowledging an employee's actions.

Failure to acknowledge results can be devastating. Not long ago, I received a telephone call from a former student who was chief operating officer for a major restaurant company. In the prior five years, he had doubled the number of restaurants and tripled the company's revenues. Despite that clearly successful record, he had just resigned. When I asked him why, he explained that the CEO of the company had never thanked him or acknowledged his efforts. Let me be clear about this: The issue wasn't money; it was acknowledgment. This happens in organizations every day due to poor leadership, and the best people can always leave.

This is far more than a matter of making people feel good, as you will see In Table 6.2. In our study, we asked the regional manager of an upscale casual dining restaurant chain to give us a list of those restaurants whose performance was highest on the dimensions of financial performance, cleanliness and maintenance, and managing people, and also to list those that were lowest on those metrics. We then asked the employees of each restaurant on both lists to describe their manager's reinforcement behaviors, as well as their feeling about a variety of emotions. The results were clear. Managers of both high-performing restaurants and low performers used contingent punishment about equally - an unpleasant but necessary management tool. But we found a real difference in the reinforcement activities by managers in the two types of restaurants. The managers of the higherperforming restaurants made greater use of contingent rewards, and less use of reward omission than did the managers in the poorly performing restaurants. Those high-performing managers were also perceived to be higher in behavioral integrity, again demonstrating the importance of that concept. All of the affective responses including satisfaction and commitment were higher in the high-performing stores. Due to the rigorous design of the study, we feel confident that the managers' reinforcement behaviors alone had a substantial impact on store performance.

Providing feedback, both through a formal performance management program and personally in daily interaction, shows your employees that their contribution to the organization is acknowledged. The restaurant managers in our study who used both contingent reward and contingent punishment were evaluated more positively by both the regional manager and their own subordinates. This study 
demonstrates why leaders must pay attention and respond to subordinates' performance to send a message that they appreciate the effort put forth by their employees and want to help them improve.

Table 6.2

Restaurant-Level Performance Analysis Results

\begin{tabular}{lcc}
\hline Leader Behaviors & Low Performance & High Performance \\
\hline Contingent Reward & 4.00 & 4.37 \\
Contingent Punishment & 4.92 & 4.84 \\
Reward Omission & 4.36 & 3.98 \\
Punishment Omission & 3.16 & 3.10 \\
Subordinate Outcomes & & \\
Behavioral Integrity & 3.31 & 3.68 \\
Affective Trust & 3.14 & 3.40 \\
Supervisor Effectiveness & 3.32 & 3.71 \\
Satisfaction with Supervisor & 3.49 & 3.77 \\
Organizational Commitment & 3.73 & 3.90 \\
\hline
\end{tabular}

Note: Numbers in bold are statistically significantly different.

\section{Step 5: Be Flexible and Willing to Adapt}

The best hospitality managers assemble a team of individuals who have complementary skills and knowledge. A trap that younger managers often fall into is confusing intelligence with knowledge. The employees you are supervising may not have the education you have, but most likely possess institutional knowledge that could be helpful for you if you seek their opinions and truly listen. One cannot, no matter who he or she is, know everything, and relying on others for help does not demonstrate weakness but instead creates a community of distributed leadership where you can capitalize on the knowledge and expertise of others. ${ }^{11}$ If you surround yourself with those who view everything the same way, someone is redundant. It's widely acknowledged that the demise of Kodak and General Motors was largely due to intelligent leaders making poor decisions because they either ignored opinions and ideas that were different from their own or never heard any differing views.

At a recent Center for Hospitality Research Roundtable where over 200 industry human resources professionals gathered, we heard one consistent theme. Count on continual change, and the more hats you can wear, the more valuable you will be to your organizations. This may seem to contradict the message in the previous paragraph regarding not being able to do everything, but the message is consistent. Do a few things well and recognize that you cannot be an expert at everything. Focus on your strengths and understand how and where to get the talent and resources you do not possess. 
Your understanding of your organization will help you determine who in the organization has the information or expertise that you need to accomplish your goals. Beyond the organization, you can identify vendors who can provide a particular product or service. With the explosion in technology affecting distribution, communication, supply chain management, and even food preparation, it is virtually impossible to keep up with all of the changes. Nonetheless, you need to monitor these changes and evaluate how they may affect your organizations.

In fact, you probably will want to enlist associates to help you determine whether you have all of the information you need to make an important decision. Then you may need help in implementing the decision. You should take advantage of the value of different ideas and knowledge that exist around you. Not only will you get the information you need to make a sound decision, which may be different than had you made it alone, but those involved in the decision will be more willing to assist with the implementation. By including others in the discussion of substantive issues, you send a message that you respect their opinions and ideas, which serves to improve your relationships. This is, in fact, another form of acknowledgment, in which you demonstrate your high regard for others' opinions and expertise and your willingness to adapt as needed.

\section{Toward Stronger Leadership}

The five leadership steps I have offered are based on 25 years of research and teaching on the topic of leadership. Unfortunately, I cannot guarantee that you will become a great leader if you follow them. But I can state with reasonable certainty that if you do not follow these steps, it's unlikely that you will make it as a leader. Understanding yourself and how you prefer to lead gives you the ability to relate well with others and to modify your approach to fit a given situation. Understanding the dynamics within your formal and informal organizations and among other organizations will help you in becoming a more effective leader because you will want to monitor and nurture important interdependent relationships in your organization. Effective leadership requires a clear articulation of a vision of the future because people want to know where they are going, why they should go there, and how their efforts will help get them there. By acknowledging good performance and correcting poor performance, your employees will see that you are focused on improving the work effort. By contrast, not responding in any way will cause your subordinates to doubt your leadership ability. Finally, be willing to adapt to situations as necessary. Recognize that you cannot be an expert at everything, and by understanding yourself, your organization, and your environment, you can know where to get the resources and expertise that you need to complement your strengths. Remember that being the manager does not 
necessarily make you a leader, but if you apply the principles in this chapter, it is possible to become one.

${ }^{1}$ I. B. Myers. Introduction to Type (Mountain View, CA: CPP, Inc., 1999).

${ }^{2}$ D. Goleman. "Leadership That Gets Results" Harvard Business Review 78(2): (2000):79-90.

${ }^{3}$ usatoday.com/nioney/companies/managenient/2008-06-22-starwood-ceo--paasschen_N.htm.

${ }^{4}$ P. F. Drucker. Classic Drucker (Boston: Harvard Business School Publishing, 2006).

${ }^{5}$ G. R. Weaver, L. K. Trevino, and B. Agle. "Somebody I Look Up To: Ethical Role Models in Organisations," Organizational Dynamics 34 (2005):313-330.

${ }^{6}$ J. P. Kotter. "Leading Change-Why Transformation Efforts Fail," Harvard Business Review 85(1): (2007):96-103.

${ }^{7}$ G. A. Rummler, and A. P. Brache. Improving Performance (San Francisco: Jossey-Bass, 1995).

${ }^{8}$ D. Krackhardt, and J. R. Hanson. "Informal Networks: the Company Behind the Chart" Harvard Business Review 71(4): (1993):104-111.

${ }^{9}$ ABC News Nightline, "The Man Behind the Marriott Empire: Bill Marriott," originally broadcast 6/21/07, Films for the Humanities \& Sciences.

${ }^{10} \mathrm{~K}$. Blanchard. The Heart of a Leader (Tulsa: Honor Books, 1999).

${ }^{11}$ Deborah Ancona, Thomas W. Malone, Wanda J. Orlikowski, and Peter M. Senge. "In Praise of the Incomplete Leader," Harvard Business Review 85(2): (2007): 1-8. 